\title{
Treatment of coxalgia in patients with grades 3-4 hip osteoarthritis
}

\author{
Ia.V. Fishchenko, A.A. Vladimirov, I.V. Roy, L.D. Kravchuk, S.P. Chornobai \\ Institute of Traumatology and Orthopedics National Academy of Medical Science of Ukraine, Kiev, Ukraine
}

Hip osteoarthritis (OA) is an important public health issue. Nonsurgical treatments including changes in lifestyle, physiotherapy, pharmacological therapy can be effective for patients with coxalgia at early stages of hip osteoarthritis. Objective To evaluate the effectiveness of percutaneous radiofrequency (RF) denervation (neuroablation) of articular sensory nerves of the hip joint for pain relief in patients with chronic hip pain. Material and methods The review included 46 patients (47 joints) with hip OA who were classified as Kellgren-Lawrence grade 3 ( $\mathrm{n}=37$ ) and Kellgren-Lawrence grade $4(n=9)$. Quantitative and qualitative assessment of pain was produced with VAS scale. The Harris Hip Score (HHS) was used to measure functionality. All patients underwent radiofrequency ablation of the articular branches of the femoral and obturator nerves. The results of treatment were evaluated at 2 weeks, 1, 3, 6 and 12 months. Results VAS scores showed significant pain relief immediately after the procedure that persisted in $69.5 \%$ of patients at 6 months and in $56.5 \%$ at 12 months with $43.5 \%$ of patients reporting dissatisfaction. HHS scores demonstrated improved quality of life in $85.2 \%$ of patients at 6 months, with patient satisfaction recorded in $58.6 \%$ at 12 months, and $41.3 \%$ reported significant deterioration. Conclusions Percutaneous RF denervation of articular sensory nerves of the hip joint was shown to be effective for pain relief in patients with severe hip OA at a short term (up to 6 months). The technique can be recommended for patients who have contraindications to hip replacement surgery.

Keywords: percutaneous radiofrequency denervation, degenerative hip arthritis, coxalgia

\section{INTRODUCTION}

Osteoarthritis (OA) is the most common type of joint disease and one of the most common orthopaedic issues, with musculoskeletal conditions being a leading cause of burden of disease [1-3]. OA is a heterogenic group of disorders of different etiology with similar biological, morphological and clinical manifestations and outcomes. OA is now considered a disease of the whole joint, including alterations in the articular cartilage, subchondral bone, synovial membrane, ligaments, capsule and periarticular muscles [2-4]. Clinical manifestations of OA can be seen at the age of 35-40 years with the incidence of osteoarthritis in the population increasing annually and ranging from 10 to $23 \%$ [4-7]. Pathological changes observed in $\mathrm{OA}$ include degradation of articular cartilage, subchondral bone thickening, osteophytes synovial inflammation, damage to the ligaments and joint capsule, which progress over time, leading to chronic pain, stiffness, deformity and limited physical function.

The use of conservative treatment with changes in lifestyle (weight loss and exercise), physical therapy (orthotics, orthopedic shoes, balneotherapy) [8], pharmacological therapy (nonsteroidal antiinflammatory drugs, chondroprotectors) [9] and intraarticular injections (corticosteroids, hyaluronic acid) can be effective in the early stages of OA. None of the treatments can contribute to the restoration of cartilage tissue and total hip replacement (THR) is offered for late-stage OA [7-10]. However, some patients may have contraindications to THR including severe co-morbid condition and socio-economic factors associated with a long waiting listand the high costs [5,9-11].Percutaneous radiofrequency (RF) denervation (neuroablation) of articular sensory nerves of the hip joint can be effectively used for pain relief in patients with chronic hip pain [1215]. Targeted thermal action on the nerve fibers leads to the inhibition of the conduction of pain impulses. This effect is called denervation [16]. Pain conduction blocks after RF denervation are reported to last up to three years and over, with physical activity being pain free in the involved joint [11-16].

Objective To evaluate the effectiveness of percutaneous radiofrequency (RF) denervation (neuroablation) of articular sensory nerves of the hip joint for pain relief in patients with chronic hip pain.

\section{MATERIAL AND METHODS}

The prospective study included 46 patients (47 joints) with hip OA who were treated as outpatients.
The average age of the patients was $64.5 \pm 1.2$ (range, 38 to 77 ) years. The average duration of pain before 
treatment was $3.6 \pm 2.3$ years. All patients were examined clinically and radiologically. Hip pain was the main complaint of the patients. Hip joints were radiologically graded with the classification of J. Kellgren and J. Lawrence [14]. Hips were classified as Kellgren-Lawrence grade $3(n=37)$ and Kellgren-Lawrence grade $4(n=9)$. Quantitative and qualitative assessment of pain was produced with VAS scale. The Harris Hip Score (HHS) was used to measure functionality.

Inclusion criteria were pain scored 5 and over on VAS scale due to hip OA, failed conservative treatment, systematic use of NSAIDs for pain relief. Exclusion criteria included chronic systemic inflammatory process, local inflammation at the site of the procedure, coagulopathy, inability for adequate body position to receive a procedure, mental illness. All patients underwent radiofrequency ablation of the articular branches of the femoral and obturator nerves. The results of treatment were evaluated at 2 weeks, 1, 3, 6 and 12 months. The study was performed in accordance with ethical principles for medical research involving human subjects stated in the Declaration of Helsinki developed by the World Medical Association as revised in 2013. Written informed consent was obtained from all patients for publication of the findings without identifying details. The research materials were formalized according to generally accepted principles and compiled into a data matrix using the Excel 13.0 tabular processor of the Microsoft Office package. Statistical data analysis was performed using Statistica for Windows computer program and IBM SPSS Version 22.0 statistic software package. The Mann-Whitney test was used to determine significant differences in the VAS pain scores at the follow-up periods.

Methodology of the procedure included the patient's supine position. The first stage was denervation of the articular branches of the obturator nerve. Sonography was used to identify the neurovascular bundle of the femur (a., v., n. femoralis). A $20 \mathrm{G}$ cannula with a $10 \mathrm{~mm}$ active portion was inserted medial to the femoral artery under the inguinal ligament or $3 \mathrm{~cm}$ laterally to the femoral artery forming an angle of $70^{\circ}$ with the sagittal plane. The cannula was placed under the inferior articulations of the sciatic bone and the pubic bone that formed a "tear drop" in the anteriorposterior view under fluoroscopic control. An electrode was inserted into the cannula with the needle position confirmed fluoroscopically and sensitive stimulation was performed at a frequency of $50 \mathrm{~Hz}$ and a voltage of $0.7 \mathrm{~V}$. An increase in pain and paresthesia in the groin was considered positive by association with the usual pain experienced by the patient. Then motor stimulation was performed at a frequency of $2 \mathrm{~Hz}$ and a voltage of $0.9 \mathrm{~V}$ to rule out an injury to the motor branches located close to the electrode. Local anesthesia was performed with $2 \mathrm{~mL} 1 \%$ lidocaine solution. Denervation of the sensitive articular branches of the femoral nerve was performed at the second stage. The anterolateral approach was used to place the cannula with the tip placed $2 \mathrm{~cm}$ below the spina iliaca inferior anterior, close to the anterolateral aspect of the hip joint. A $2 \mathrm{~mL}$ $1 \%$ lidocaine solution was injected after sensitive and motor stimulation. RF neuro-coagulation of the articular branches of the obturator and femoral nerves was performed at a temperature of $90^{\circ}$ for $90 \sec 2-3$ minutes following the local anesthetic administeration.

\section{RESULTS}

The dynamics in subjective pain on the VAS scale measured before and after treatment and the assessment of functional limitations with HHS scores are shown in Figures 1 and 2. A decrease in pain intensity by $3 \mathrm{~cm}$ on the VAS scale and over was considered significant at the treatment stages. The average level of pain decreased from $7.2 \pm 0.3$ to $4.0 \pm 0.29$ scores $(p<0.05)$ in the group at a 14-day follow-up. The positive dynamics in pain intensity persisted elsewhere measuring $3.2 \pm 0.23$ at 1 month, $4.0 \pm 0.34$ at 3 months, $3.7 \pm 0.26$ at 6 months, $4.1 \pm 0.3$ at 12 months, respectively $(\mathrm{p}<0.05)$. Patients reported improvements by $3 \mathrm{~cm}$ or more on VAS scale $(\mathrm{p}<0.05)$ from RF denervation procedures at 14 days $(\mathrm{n}=32 ; 69.5 \%)$, at 1 month $(\mathrm{n}=36 ; 78.2 \%), 3$ months $(\mathrm{n}=35 ; 76.1 \%), 6$ months $(\mathrm{n}=32 ; 69.5 \%)$ and 12 months $(\mathrm{n}=26 ; 56.5 \%)$.

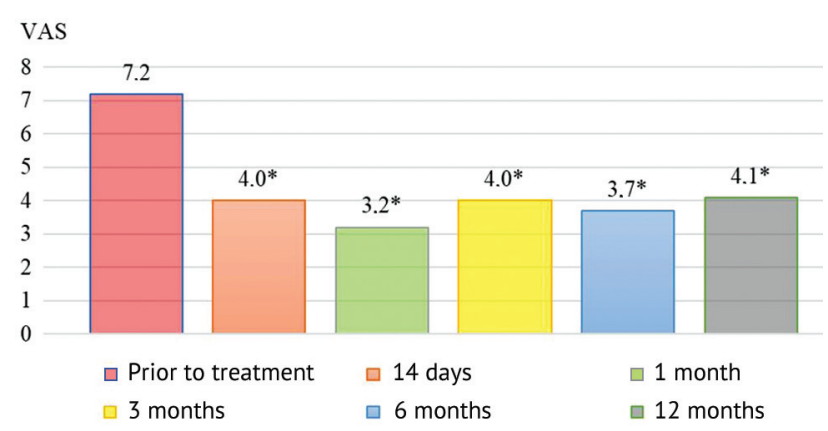

Fig. 1 The dynamics in subjective pain measured on VAS scale $(\mathrm{cm})$ before treatment and at follow-up periods of RF denervation. Note: ${ }^{*}$ - a significant difference with the initial parameter measured with the Mann-Whitney test $(\mathrm{p}<0.05)$

Insignificant improvements or absence of pain dynamics on the VAS scale were observed at 14 days following $\mathrm{RF}$ denervation $(\mathrm{n}=14 ; 30.5 \%)$, at 1 month $(\mathrm{n}=10 ; 21.8 \%), 3$ months $(\mathrm{n}=11 ; 23.9 \%)$, 
6 months $(\mathrm{n}=14 ; 30.5 \%)$ and at 12 months $(\mathrm{n}=20$; $43.5 \%$ ) (Fig. 2).

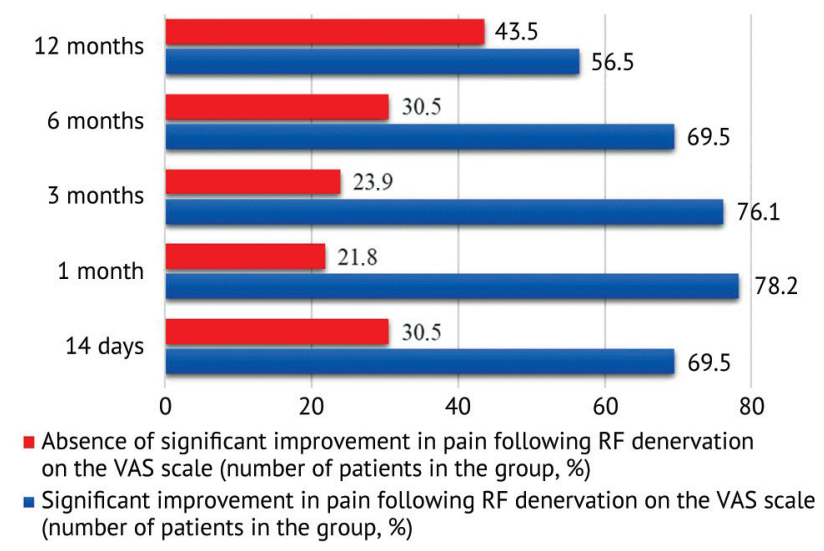

Fig. 2 Evaluation of the effectiveness of hip pain treated with RF denervation with the VAS scores measured in patients with hip OA at the follow-up periods (number of patients in the group, \%). Note: A decrease in pain intensity by $3 \mathrm{~cm}$ on the VAS scale and over was considered significant at the treatment stages.

The results obtained demonstrated the effectiveness of the RF denervation procedure in patients with coxalgia at a short term with the positive effect maintained at 6 months in $69.5 \%$ of the the cases. However, $56.5 \%$ of the patients returned to the pain intensity at the baseline level at 12 months and the RF denervation technique of of the articular branches of the femoral and obturator nerves appeared to be effective for at least six months. The Harris Hip Score (HHS) was used to measure functionality and quality of life of patients with hip arthritis who underwent the $n$. obturatorius and $n$. femoralis RF denervation procedure. A 26-score increase in the HHS was considered a significant improvement. The mean HHS score steadily improved among the patients from $24.4 \pm 0.74$ at baseline to $51.2 \pm 1.6$ at 14 days, to $61.2 \pm 2.3$ at 1 month, to $58.3 \pm 2.2$ at 3 months, to $56.3 \pm 2.3$ at 6 months, to $55.1 \pm 2.1$ at 12 months of RF denervation. Significant improvements in HHS scores were observed at 14 days following $\mathrm{RF}$ denervation $(\mathrm{n}=38 ; 82.6 \%)$, at 1 month $(\mathrm{n}=35 ; 76.1 \%)$, at 3 months $(\mathrm{n}=31$; $67.4 \%), 6$ months $(\mathrm{n}=30 ; 65.2 \%)$, at 12 months $(\mathrm{n}=27 ; 58.6 \%)$ (Fig. 3).

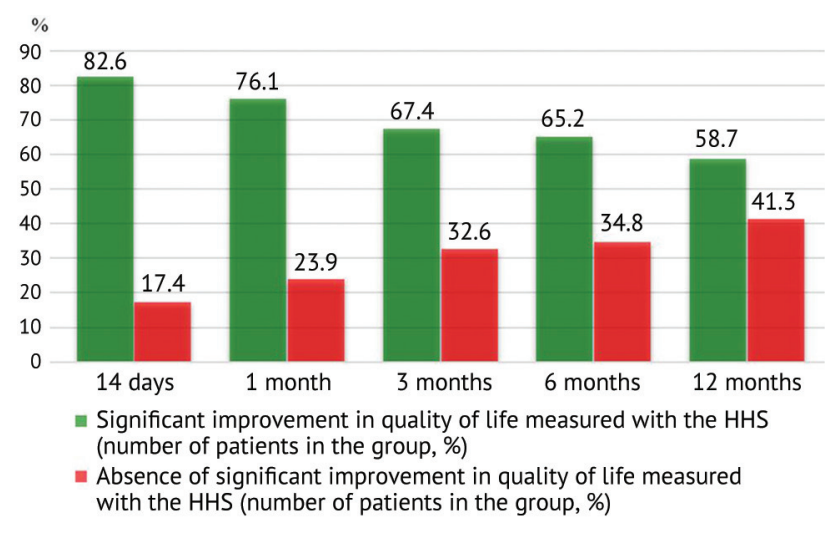

Fig. 3 Dynamics in the HHS scores in patients with hip OA thoughout the follow-up periods (number of patients in the group, \%)

Thus, $19(41.3 \%)$ patients reported a lack of dynamics or insignificant improvements at a 12-month follow-up as compared to the baseline.

Complications. Most of the procedures occurred without complications. Adverse events following the RF denervation included an inguinal hematoma resulting from an injury to the a. femoralis $(n=1)$ and hypostesia on the anterior aspect of the femur resulting from an injury to the $\mathrm{n}$. anterior femoralis cutaneous $(n=2)$ at the site of thermocoagulation of the articular branches of the femoral nerve.

\section{DISCUSSION}

Denervation at the hip joint in patients with hip pain due to arthritis is not a new procedure. Before the THR was commonly used in orthopedic practice, denervation had been intensely applied to relieve pain in OA. Neurectomy of the obturator nerve was first performed by H. Camitz in 1933 [16] and W. Mol in 1935 [17]. L. Tavernier and C. Godinot [18] reported successful results of open neurectomy of the obturator nerve in 22 of 57 patients with hip arthritis. Combined neurectomy of the obturator and femoral nerves showed a good, but short-term effect (up to 3 months) in 22 of 24 patients. Two patients reported good results of treatment at 3 and 18 months, respectively [19].

M. Kawaguchi et al. [20] showed the effectiveness of radiofrequency neuroablation in 11 patients $(79 \%)$ and no effect in 3 . Twelve patients reported a regression of hip pain $>50 \%$ for a period of 1 to 11 months. One patient whose outcome was rated as ineffective showed a significantly reduction in pain in the groin area, but the pain persisted on the lateral aspect of the femur. Because of this, the authors performed diagnostic blockages of the obturator nerve before the neuroablation procedure for subsequent patients. Neuroablation of the articular branches of the obturator and the femoral nerves was produced with insufficient pain regression achieved with the blockade. A. Malik et al. [15] reported the results of denervation of the articular branches of the femoral and obturator nerves in 4 patients. Regression of the pain was noted in $30-70 \%$ of the patients with functional improvement seen in 3 of 4 patients and decreased doses of analgesics in 2 patients. $\mathrm{H}$. Wu and J. Groner [21] used pulsed RF neuroablation 
in 2 patients. Compared to thermal neuroablation, the pulse mode did not cause tissue coagulation at lower temperatures $\left(42-45^{\circ}\right)$ but required a more precise location of the electrode to be placed strictly perpendicular to the nerve. Both patients reported a reduction in pain and functional improvement at a short-term follow-up.

S. Fukui and S. Nosaka [22] reported a significant reduction in pain, functional improvements and a significant reduction in the use of painkillers for more than 6 months after RF neuroablation of the articular branches of the femoral and obturator nerves in one patient. On the whole, the studies on RF neuroablation of the hip joint nerves we reviewed were of a poor quality with a small sample size, poorly described methodology for selecting patients with heterogeneous etiology of pain (OA, avascular necrosis, metastases, postoperative condition), different electrode placement, and lack of analysis of functional results. However, all studies have shown relative safety of the procedures with hypostesia on the anterior aspect of the femur seen in one patient and hematomas at the site of the procedure observed in several cases. Although the RF denervation is not an alternative to THR the procedure can relieve pain for the period of 6 months to 12 months. The RF denervation technique can be a good alternative for patients with grades 3 and 4 hip $\mathrm{OA}$ and failed conservative treatments. In addition, the method can be helpful in pain relief in the early postoperative period of THR.

\section{CONCLUSIONS}

1. OA is the most common type of joint disease and one of the most common orthopedic issues, with musculoskeletal conditions being a leading cause of burden of disease. Nonsurgical treatments including changes in lifestyle, physiotherapy, pharmacological therapy can be effective for patients with coxalgia at early stages of hip osteoarthritis.
2. Percutaneous RF denervation of articular sensory nerves of the hip joint was shown to be effective for pain relief in patients with severe hip OA at a short term (up to 6 months). However, the technique failed to prevent the progression of the underlying disease, and should be used in combination with other methods of conservative treatment.

\section{REFERENCES}

1. Murray K.J., Molyneux T., Le Grande M.R., Castro Mendez A., Fuss F.K., Azari M.F. Association of Mild Leg Length Discrepancy and Degenerative Changes in the Hip Joint and Lumbar Spine. J. Manipulative Physiol. Ther., 2017, vol. 40, no. 5, pp. 320-329. DOI: 10.1016/j. jmpt.2017.03.001

2. Oner A., Koksal A., Sofu H., Aykut U.S., Yıldırım T., Kaygusuz M.A. The prevalence of femoroacetabular impingement as an aetiologic factor for end-stage degenerative osteoarthritis of the hip joint: analysis of 1,000 cases. Hip Int., 2016, vol. 26, no. 2, pp. 164-168. DOI: 10.5301/hipint.5000323

3. Gupta G., Radhakrishna M., Etheridge P., Besemann M., Finlayson R.J. Radiofrequency denervation of the hip joint for pain management: case report and literature review. US Army Med. Dep. J., 2014, Apr-Jun, pp. 41-51.

4. Yoshimoto K., Hamai S., Higaki H., Gondoh H., Shiomoto K., Ikebe S., Hara D., Komiyama K., Nakashima Y. Dynamic hip kinematics before and after periacetabular osteotomy in patients with dysplasia. J. Orthop. Sci., 2020, vol. 25, no. 2, pp. 247-254. DOI: 10.1016/j.jos.2019.03.019

5. Tinnirello A., Todeschini M., Pezzola D., Barbieri S. Pulsed Radiofrequency Application on Femoral and Obturator Nerves for Hip Joint Pain: Retrospective Analysis with 12-Month Follow-up Results. Pain Physician, 2018, vol. 21, no. 4, pp. 407-414.

6. Gaiko G.V., Kalashnikov A.V., Chalaidiuk T.P. Diagnostychnoprognostychnyj algorytm progresuvannya osteoartrozu kul'shovogo sugloba [Diagnostic-prognostic algorithm of hip osteoarthrosis progression]. Ukraïnskii Morfologichnii Almanakh, 2013, vol. 11, no. 1, pp. 58-61. (in Ukrainian)

7. Hernández-González L., Calvo C.E., Atkins-González D. Peripheral Nerve Radiofrequency Neurotomy: Hip and Knee Joints. Phys. Med. Rehabil. Clin. N. Am., 2018, vol. 29, no. 1, pp. 61-71. DOI: 10.1016/j.pmr.2017.08.006

8. Bhatia A., Hoydonckx Y., Peng P., Cohen S.P. Radiofrequency Procedures to Relieve Chronic Hip Pain: An Evidence-Based Narrative Review. Reg. Anesth. Pain Med., 2018, vol. 43, no. 1, pp. 72-83. DOI: 10.1097/AAP.0000000000000694

9. Arboleda M.F., Girón-Arango L., Peng P.W.H. Can recent chronic pain techniques help with acute perioperative pain? Curr. Opin. Anaesthesiol., 2019, vol. 32, no. 5, pp. 661-667. DOI: 10.1097/ACO.0000000000000772.

10. Aresti N., Kassam J., Nicholas N., Achan P. Hip osteoarthritis. BMJ, 2016, vol. 354, pp. i3405. DOI: 10.1136/bmj.i3405

11. Murphy N.J., Eyles J.P., Hunter D.J. Hip Osteoarthritis: Etiopathogenesis and Implications for Management. Adv. Ther., 2016, vol. 33, no. 11, pp. 1921-1946. DOI: 10.1007/s12325-016-0409-3

12. Cibulka M.T., Bloom N.J., Enseki K.R., Macdonald C.W., Woehrle J., McDonough C.M. Hip Pain and Mobility Deficits-Hip Osteoarthritis: Revision 2017. J. Orthop. Sports Phys. Ther., 2017, vol. 47, no. 6, pp. A1-A37. DOI: 10.2519/jospt.2017.0301

13. Racz G.B., Noe C.E., eds. Techniques of Neurolysis. $2^{\text {nd }}$ Ed. Springer International Publishing, 2016, 211 p. DOI: 10.1007/978-3-319-27607-6.

14. Kellgren J.H., Lawrence J.S. Radiological assessment of rheumatoid arthritis. Ann. Rheum. Dis., 1957, vol. 16, no. 4, pp. 485-493. DOI: 10.1136/ ard.16.4.485

15. Malik A., Simopolous T., Elkersh M., Aner M., Bajwa Z.H. Percutaneous radiofrequency lesioning of the sensory branches of obturator and femoral nerves for the treatment of non-operable hip pain. Pain Physician, 2003, vol. 6, no. 4, pp. 499-502.

16. Camitz H. Die deformierende hüftgelenksarthritis und speziell IHRE behandlung [Deforming hip arthritis and especially YOUR treatment]. Acta Orthop. Scand., 1933, vol. 4, no. 3, pp. 193-213. DOI: 10.3109/17453673308988867. (in German)

17. Mol W. De resectie van den nervus obturatorius bij arthritis deformans van hel heupgewricht [The resection of the obturator nerve in arthritis deformans of the hip joint]. Ned. Tijdschr. Geneeskd. (NTvG), 1935, vol. 79, pp. 850-855. (in Dutch)

18. Tavernier L., Godinot C.H. Traitement chirurgical de l'arthrite sèche de la hanche. Suivi de travaux de la Clinique de L Faculte de Lyon [Surgical treatment of dry arthritis of the hip: Monitoring of the work of the Clinique de L'Faculte de Lyon]. Paris: Masson \& Cie. 1945.

19. Quinn R.H., Murray J., Pezold R., Hall Q. Management of Osteoarthritis of the Hip. J. Am. Acad. Orthop. Surg., 2018, vol. 26, no. 20, pp. e434-e436. DOI: $10.5435 /$ JAAOS-D-18-00351

20. Kawaguchi M., Hashizume K., Iwata T., Furuya H. Percutaneous radiofrequency lesioning of sensory branches of the obturator and femoral nerves for the treatment of hip joint pain. Reg. Anesth. Pain Med., 2001, vol. 26, no. 6, pp. 576-581. DOI: 10.1053/rapm.2001.26679 
21. Wu H., Groner J. Pulsed radiofrequency treatment of articular branches of the obturator and femoral nerves for management of hip joint pain. Pain Pract., 2007, vol. 7, no. 4, pp. 341-344. DOI: 10.1111/j.1533-2500.2007.00151.x

22. Fukui S., Nosaka S. Successful relief of hip joint pain by percutaneous radiofrequency nerve thermocoagulation in a patient with contraindications for hip arthroplasty. J. Anesth., 2001, vol. 15, no. 3, pp. 173-175. DOI: $10.1007 / \mathrm{s} 005400170023$

Received: 28.07 .2020

\section{Information about the authors:}

1. Iakiv V. Fishchenko, M.D., Ph.D.,

Institute of Traumatology and Orthopedics the National Academy of Medical Sciences of Ukraine, Kyiv, Ukraine

2. Alexander A. Vladimirov, M.D., Ph.D., Professor,

National Medical Academy of Postgraduate Education named after P.L. Shupika, Kyiv, Ukraine

3. Irina V. Roy, M.D., Ph.D., Professor,

Institute of Traumatology and Orthopedics the National Academy of Medical Sciences of Ukraine, Kyiv, Ukraine

4. Lyudmila D. Kravchuk, Ph.D.,

National University of Physical Education and Sport of Ukraine (NUPESU), Kyiv, Ukraine,

Email:kravchukwww@gmail.com

5. Serhii P. Chornobai, M.D.,

Institute of Traumatology and Orthopedics the National Academy of Medical Sciences of Ukraine, Kyiv, Ukraine 